\title{
RESEARCH
}

Open Access

\section{Forsythoside B attenuates memory impairment and neuroinflammation via inhibition on NF-kB signaling in Alzheimer's disease}

Fan'ge Kong ${ }^{1 \dagger}$, Xue Jiang ${ }^{1 \dagger}$, Ruochen Wang ${ }^{1}$, Siyu Zhai ${ }^{1}$, Yizhi Zhang ${ }^{2^{*}}$ and Di Wang ${ }^{1 *}$ (1)

\begin{abstract}
Background: Neuroinflammation is a principal element in Alzheimer's disease (AD) pathogenesis, so anti-inflammation may be a promising therapeutic strategy. Forsythoside B (FTS•B), a phenylethanoid glycoside isolated from Forsythiae fructus, has been reported to exert anti-inflammatory effects. However, no studies have reported whether the antiinflammatory properties of FTS B have a neuroprotective effect in AD. In the present study, these effects of FTS.B were investigated using amyloid precursor protein/presenilin 1 (APP/PS1) mice, BV-2 cells, and HT22 cells.
\end{abstract}

Methods: APP/PS1 mice were administered FTS•B intragastrically for 36 days. Behavioral tests were then carried out to examine cognitive functions, including the Morris water maze, Y maze, and open field experiment. Immunohistochemistry was used to analyze the deposition of amyloid-beta $(A \beta)$, the phosphorylation of tau protein, and the levels of 4-hydroxynonenal, glial fibrillary acidic protein, and ionized calcium-binding adapter molecule 1 in the hippocampus. Proteins that showed marked changes in levels related to neuroinflammation were identified using proteomics and verified using enzyme-linked immunosorbent assay and western blot. BV-2 and HT22 cells were also used to confirm the anti-neuroinflammatory effects of FTS.B.

Results: In APP/PS1 mice, FTS•B counteracted cognitive decline, ameliorated the deposition of A $\beta$ and the phosphorylation of tau protein, and attenuated the activation of microglia and astrocytes in the cortex and hippocampus. FTS•B affected vital signaling, particularly by decreasing the activation of JNK-interacting protein 3/C-Jun NH2-terminal kinase and suppressing WD-repeat and FYVE-domain-containing protein 1/toll-like receptor 3 (WDFY1/TLR3), further suppressing the activation of nuclear factor-kB (NF-kB) signaling. In BV-2 and HT22 cells, FTS•B prevented lipopolysaccharide-induced neuroinflammation and reduced the microgliamediated neurotoxicity.

Conclusions: FTS•B effectively counteracted cognitive decline by regulating neuroinflammation via NF-KB signaling in APP/PS1 mice, providing preliminary experimental evidence that FTS•B is a promising therapeutic agent in $A D$ treatment.

Keywords: Forsythoside B, Alzheimer's disease, Neuroinflammation, NF-kB

\footnotetext{
* Correspondence: yzzhang@jlu.edu.cn; jluwangdi@outlook.com

${ }^{\dagger}$ Fan'ge Kong and Xue Jiang contributed equally to this work.

${ }^{2}$ Department of Neurology, the Second Hospital of Jilin University, Jilin University, Changchun 130041, China

${ }^{1}$ School of Life Sciences, Jilin University, Changchun 130012, China
} 


\section{Background}

Alzheimer's disease (AD) is the main cause of dementia, which will affect 131.5 million people worldwide by 2050 [1]. AD patients are characterized by extracellular plaques of aggregated amyloid-beta $(A \beta)$ and neurofibrillary tangles composed of hyperphosphorylated tau protein, and neuronal loss in their central nervous system. AD patients show clinical symptoms of memory loss, cognitive disorder, and neuropsychiatric symptoms, and require heavy economic cost on patient care and treatment [2]. However, the current treatment methods have problems of inefficiency, tolerance, and side-effects [3]. N-methyl-Daspartate receptor antagonists only relieve dementia symptoms for a limited time and cannot stop or reverse AD progression [3]. Acetylcholinesterase inhibitors lose efficacy after chronic usage and have uncontrollable adverse effects [4]. Finally, long-term prophylactic use of non-steroidal anti-inflammatory drugs may reduce the risk of $\mathrm{AD}$ development, although the harmful side effects of these drugs limit their use [5].

Neuroinflammation is demonstrated to involve in AD pathogenesis by a large amount of evidence [6]. Neuroinflammation is characterized by reactive gliosis surrounding the amyloid plaques. The activation of chronic glial and the production of pro-inflammatory cytokine stimulate neurodegenerative, which are observed in AD patients and animal models [7]. Inflammation activated microglia and astrocytes produce tumor necrosis factoralpha (TNF- $\alpha$ ) and nitric oxide (NO) to exacerbate neuronal damage in several neurodegenerative diseases $[8,9]$. Activated microglia and astrocytes produce interleukin (IL) -6 and IL-1 $\beta$ to increase the level of amyloid-beta precursor protein (APP) and promote $A \beta$ deposition in $\mathrm{AD}$ mice models [10]. Nuclear factor $-\mathrm{k} B(\mathrm{NF}-\mathrm{kB})$ is also activated in microglia and astrocytes and aggravates neurodegeneration in rat hippocampus $[11,12]$. Therefore, the control of neuroinflammation may be a feasible therapeutic strategy in AD.

Natural products with anti-inflammatory actions may exert positive effects in patients with AD [13]. Forsythiae Fructus, the fruit of Forsythia suspensa (Thunb.) Vahl, has traditionally been used to treat inflammation and pyrexia in Korea, China, and Japan [14]. More than 30 phenylethanoid glycosides that exhibit anti-inflammatory, antibacterial, and anti-oxidant effects have been isolated from Forsythiae Fructus [15]. We have found that forsythoside $\mathrm{B}$ (FTS•B), which has the chemical structure $\mathrm{C}_{34} \mathrm{H}_{44} \mathrm{O}_{19}$ (Figure S1), exhibits better neuroprotection than other phenylethanoid glycosides of Forsythiae Fructus based on cell screening. FTS•B alleviates lipopolysaccharide (LPS)induced acute lung injury by attenuating the infiltration of inflammatory cells and suppressing the activation of tolllike receptor (TLR)4/NF-kB signaling [16]. FTS•B suppresses the activation of NF- $\mathrm{kB}$ and ameliorates excessive inflammatory responses in sepsis patients [17]. FTS•B can rescue cardiac function by exerting an antioxidant effect that suppresses the inflammatory response [18]. However, FTS.B has not been addressed in the study of neuroprotection or modulation of neuroinflammation.

Therefore, we hypothesize FTS $\cdot \mathrm{B}$ is anti-inflammatory and neuroprotective in $\mathrm{AD}$ mice. By using amyloid precursor protein/presenilin 1 (APP/PS1) AD mice model, we found FTS.B ameliorated AD-like behaviors, prevented histopathological alterations, improved biochemical indicators, and suppressed the inflammatory response by regulating the $N F-k B$ signaling pathway. In BV-2 microglial cells and hippocampal HT22 cells, we found FTS•B prevented lipopolysaccharide-induced neuroinflammation and reduced the microglia-mediated neurotoxicity. We provide evidence that FTS $\bullet$ B could be used to treat neuroinflammation in AD.

\section{Methods \\ Cell culture}

BV-2 microglial cells (CL-0493; Procell Life Science \& Technology Co. Ltd., Wuhan, China) and HT22 cells (337709; BeNa Culture Collection, Beijing, China) were cultured in Dulbecco's modified Eagle's medium (DMEM; Gibco, Grand Island, NY) supplemented with $10 \%$ fetal bovine serum (Procell Life Science \& Technology Co. Ltd.), $1 \% 100 \mu \mathrm{g} / \mathrm{mL}$ streptomycin and 100 units/mL penicillin (Gibco, Grand Island, NY, USA). The cells were maintained at $37{ }^{\circ} \mathrm{C}$ in a humidified incubator containing $5 \% \mathrm{CO}_{2}$ (Thermo Fisher Scientific Inc., Waltham, MA, USA).

\section{Cell viability and apoptosis assay}

BV-2 cells seeded into 96-well plates were pretreated with $1 \mu \mathrm{M}$ and $2.5 \mu \mathrm{M}$ FTS.B (98\%; Shanghai Yuanye BioTechnology Co. Ltd., Shanghai, China) or phosphatebuffered saline (PBS) for $3 \mathrm{~h}$. They were then co-incubated with $1 \mu \mathrm{g} / \mathrm{mL}$ LPS (Sigma-Aldrich, St. Louis, MO, USA) dissolved in DMEM for $24 \mathrm{~h}$. Cell viability was analyzed using the 3-(4,5-dimethyl-2-thiazolyl) 2,5-diphenyl-2Htetrazolium bromide (MTT; Sigma-Aldrich, USA) assay, as in our previous study [19].

In a separate experiment, BV-2 cells were preincubated with $1 \mu \mathrm{M}$ and $2.5 \mu \mathrm{M}$ FTS $\bullet \mathrm{B}$ or PBS at $37^{\circ} \mathrm{C}$ for $3 \mathrm{~h}$. They were then co-incubated with $1 \mu \mathrm{g} / \mathrm{mL}$ LPS for $24 \mathrm{~h}$ and the culture media were collected. HT22 cells seeded into 12-well plates were then exposed to the collected medium for another $24 \mathrm{~h}$. Cell viability and apoptosis of HT22 cells were analyzed using the MTT assay and annexin V/propidium iodide (AV/PI) staining, as in our previous study [20]. 


\section{Animal study \\ Acute toxicity test}

Male C57 mice (8 weeks, 20-25 g) obtained from Liaoning Changsheng Biotechnology Co. Ltd. (Liaoning, China) were used to evaluate the acute toxicity of FTS $\bullet$ B. The mice were given $400 \mathrm{mg} / \mathrm{kg}$ FTS $\bullet \mathrm{B}$ via intragastric administration ( $n=8$ /group). After FTS•B treatment, they were observed continuously for the first $4 \mathrm{~h}$ to monitor mortality and abnormal behaviors and then observed intermittently over the next $24 \mathrm{~h}$. Thereafter, they were observed occasionally for the remainder of the 14day study period to monitor any delayed effects. The mice were sacrificed on the 14th day after drug administration. Histological sections were taken to examine any damage to the liver, spleen, kidney, and brain [21].

\section{Experiments performed on $A D$ mice and agent administration protocol}

Twenty-four double-transgenic (APPswePSEN1dE9/Nju) male B6C3-Tg mice aged 8 months and weighing 40-45 g were purchased from Nanjing Biomedical Research Institute of Nanjing University, Jiangsu, China (SCXK (SU) 2015-0001). The mice had the following genotype: (Appswe) T, (Psen1) T, and are referred to here as APP/ PS1 mice. Eight wild type (WT) male mice of the same age and weight were also purchased. Their genotype was (Appswe) W, (Psen1) W. The mice were maintained under standard conditions (temperature: $23^{\circ} \mathrm{C} \pm 1{ }^{\circ} \mathrm{C}$, humidity: 40-60\%) with a 12-h light/dark cycle and food available ad libitum.

After a week of adjustable feeding, the APP/PS1 mice were randomly divided into three groups ( $n=8$ /group) and intragastrically administered either $10 \mathrm{mg} / \mathrm{kg} \mathrm{FTS} \bullet \mathrm{B}$, $40 \mathrm{mg} / \mathrm{kg}$ FTS•B, or $5 \mathrm{~mL} / \mathrm{kg}$ normal saline (model group) once a day for 36 days. Eight WT mice were orally administered $5 \mathrm{~mL} / \mathrm{kg}$ normal saline for 36 days (control group). After the last behavioral test, the mice were euthanized by injection with $150 \mathrm{mg} / \mathrm{kg} 1.5 \%$ pentobarbital. Serum and tissues, including the brain, liver, spleen, and kidney, were collected for biochemical and histopathological analysis. The drug administration process and behavioral tests are shown in Figure S2.

\section{Behavioral tests}

\section{Morris water maze test}

Brain function related to spatial learning and memory was assessed in the AD mice using the Morris water maze (MT-200; Chengdu, China) and the Water Labyrinth Video Tracking Analysis System (S7200; Chengdu Techman Software Co. Ltd., Chengdu, China). A circular pool was filled with water containing milk at a temperature of $22-24{ }^{\circ} \mathrm{C}$. A platform was placed $1 \mathrm{~cm}$ below the water surface and the pool was used for both training and experiment. Starting on the 29th day, the mice were trained for $5 \mathrm{~min} /$ day over 4 days. On the 33rd day, they were placed in the same quadrant of the pool, and the escape latency of mice to locate the hidden platform was recorded, up to a maximum of $60 \mathrm{~s}$ [20].

\section{$Y$ maze test}

The spontaneous alteration test was assessed in a $Y$ maze with three symmetrical arms measuring $300 \times 200$ $\mathrm{mm}$ at a $120^{\circ}$ angle. The mice's movements were recorded using a video camera mounted above the maze. On the 34th day, the mice were placed onto the distal end of one arm and expected to find the food on the other end within $5 \mathrm{~min}$, which was the maximum time allowed by the system. On the 35th day, the time taken to find the food and the movement locus of the mice were recorded using the video camera [22].

\section{Open field experiment}

The open-field experiment test was performed in a soundproof dark box (bottom area: $30 \times 30 \mathrm{~cm}$, central region: $15 \times 15 \mathrm{~cm}$ ) to observe the mice's autonomous behaviors in the new environment. On the 36th day, the mice were placed in a fixed central location and allowed to explore the environment freely for $5 \mathrm{~min}$. The moving track and latency time of the mice in the center and surrounding areas were recorded by the instrument. The box was cleaned thoroughly after each individual test to avoid residual odors and dirt interfering with the results of the next test [23].

\section{Biochemical criteria detection}

BV-2 cells were pretreated with FTS $\bullet$ B at doses of $1 \mu \mathrm{M}$ and $2.5 \mu \mathrm{M}$ for $3 \mathrm{~h}$. They were then co-exposed to $1 \mu \mathrm{g} /$ $\mathrm{mL}$ LPS for another $24 \mathrm{~h}$. The levels of IL-6 (cat. No. KT2163-A), TNF- $\alpha$ (KT2132-A), inducible nitric oxide synthase (iNO ; KT2454-A), NO (MM-0658 M1), and IL$1 \beta$ (KT2040-A) in the supernatant were measured using enzyme-linked immunosorbent assay (ELISA) kits (Jiangsu Kete Biotechnology Co., Ltd, Jiangsu, China) according to the manufacturer's instructions.

The brain obtained from the APP/PS1 mice were homogenized in ice-cold PBS, and the protein concentration was detected using the Pierce ${ }^{\mathrm{Tm}}$ bicinchoninic acid (BCA) protein assay kit (23227; Thermo Fisher Scientific, USA). The levels of the following factors were detected in the serum and the brain using ELISA kits, according to the manufacturer's instructions (Jiangsu Kete Biotechnology Co. Ltd, Jiangsu, China): TLR3 (cat. No. KT9375-A), interferon regulating factor 3 (IRF3; KT9374-A), phosphor (p)-IRF3 (MM-50143 M1), interferon-beta (IFN- $\beta$; KT2124-A), C-Jun NH2terminal kinase (JNK; KT9182-A), JNK-interacting protein 3 (JIP3; KT9377-A), p-JNK (KT9372-A), APP (KT2824-A), pAPP (KT9378-A), A $\beta$ (KT9256-A), TNF- $\alpha$ (KT2132-A), IL- 
$1 \beta$ (KT2040-A), IL-6 (KT2163-A), IL-8 (KT2123-A), and IL12 (KT2105-A).

\section{Hematoxylin and eosin (H\&E) staining, thioflavine $S$ staining, and immunohistochemistry examination}

As in our previous study [24], 4\% paraformaldehydefixed liver, spleen, kidney, and brain tissues were dehydrated using alcohol, embedded in paraffin, and cut into $5-\mu \mathrm{m}$ standard sections. Specimens were stained using $\mathrm{H} \& \mathrm{E}$ and assessed using an inverted microscope (CKX41; Olympus, Japan).

Thioflavine $\mathrm{S}$ staining was used to visualize fibrillar $\mathrm{A} \beta$ deposits. After rehydration using xylene and a graded series of ethanol solutions, the brain slices were incubated with $1 \%$ thioflavine $\mathrm{S}$ in the dark for $30 \mathrm{~min}$. They were then differentiated in $70 \%$ ethanol and washed with distilled water. After fixing with $50 \%$ glycerin in PBS, slices were observed using a fluorescent microscope (magnification $\times 100$; Olympus Corporation, Tokyo, Japan) [25].

The brain sections were prepared as in our previous study [26]. The sections were incubated with primary antibodies against A $\beta$ (dilution ratio 1:1000; ab2539), ptau (p-s396; dilution ratio 1:4000; ab109390), 4hydroxynonenal (4-HNE; dilution ratio 1:200; ab46545; Abcam, Cambridge, MA, USA), glial fibrillary acidic protein (GFAP; dilution ratio 1:200; bs-0199R), and ionized calcium-binding adapter molecule 1 (Iba1; dilution ratio 1:200; bs-1363R; Bioss Inc., Beijing, China) at $4{ }^{\circ} \mathrm{C}$ overnight. The following day, the sections were washed in PBS, incubated with horseradish peroxidase (HRP)-conjugated anti-rabbit secondary antibody (sc-3836; Santa Cruz Biotechnology Inc., Dallas, TX, USA) at $25^{\circ} \mathrm{C}$ for 1 $h$, and incubated with streptavidin-organism HRP complex (Shanghai BestBio Science, Shanghai, China) at $25^{\circ} \mathrm{C}$ for another $1 \mathrm{~h}$. Next, $5 \%$ diaminobenzidine tetrahydrochloride solution and hematoxylin were added to the slices to counterstain $\left(25^{\circ} \mathrm{C}\right.$ for $\left.5 \mathrm{~min}\right)$. Photomicrographs were obtained using an inverted fluorescent microscope (magnification $\times 40$ and $\times 200$; Olympus Corporation, Tokyo, Japan).

\section{Proteomics}

\section{Protein extraction and digestion}

Samples were homogenized in radio immunoprecipitation assay (RIPA) buffer containing 1\% protease inhibitor cocktail (Sigma-Aldrich, St. Louis, MO, USA) and $2 \%$ phenylmethanesulfonyl fluoride (PMSF; Sigma-Aldrich, St. Louis, MO, USA) on ice for $30 \mathrm{~min}$. After centrifugation, a BCA protein assay kit was used to quantify protein concentrations in the supernatant. After acetone precipitation, resuspension of the protein for tryptic digest, and removal of sodium deoxycholate, peptide samples were obtained. These were then desalted using reversed-phase chromatography on a $\mathrm{C}_{18}$ column, dried, and resuspended in buffer containing $0.1 \%$ formic acid (FA) and $2 \%$ acetonitrile (ACN).

\section{Liquid chromatography coupled to tandem mass spectrometry}

One microgram of peptide was separated and analyzed using an Easy-nLC1200 nano-UPLC (Thermo Scientific, Waltham, MA) connected to a Q-Exactive mass spectrometer (Thermo Scientific, Waltham, MA). Separation was performed using a reversed-phase column $(100 \mu \mathrm{m}$, ID $\times 15 \mathrm{~cm}$, Reprosil-Pur 120 C18-AQ, $1.9 \mu \mathrm{m}$, Dr. Math). A non-linear gradient was established using phase $\mathrm{A}(0.1 \% \mathrm{FA}$ and $2 \% \mathrm{ACN}$ in water) and phase $\mathrm{B}$ (0.1\% FA and $80 \% \mathrm{ACN}$ in water) to elute the peptides, with a $120-\mathrm{min}$ gradient at a $300-\mathrm{nL} / \mathrm{min}$ flow rate. The gradient started at $8 \%$ phase $\mathrm{B}$ and was increased to $35 \%$ over $92 \mathrm{~min}$. Phase B was increased to $45 \%$ over the next $20 \mathrm{~min}$, then augmented to $100 \%$ over $2 \mathrm{~min}$ and kept at $100 \%$ for 2 min. Data-dependent acquisition for MS1 was performed in the profile and positive modes using an Orbitrap analyzer at a resolution of 70,000 $(200 \mathrm{~m} / \mathrm{z})$ and an $\mathrm{m} / \mathrm{z}$ range of $350-1600$. For $\mathrm{MS} 2$, the resolution was set to 17,500 , with a dynamic first mass. The automatic gain control target for MS1 was set to $3.0 \mathrm{E}^{+6}$, with a maximum injection time (IT) of $50 \mathrm{~ms}$, while that for MS2 was set to $5.0 \mathrm{E}^{+4}$, with a max IT of $100 \mathrm{~ms}$. The top 20 most intense ions were fragmented using higher-energy collisional dissociation, with a normalized collision energy of $27 \%$ and an isolation window of $2 \mathrm{~m} /$ z. The dynamic exclusion time window was $30 \mathrm{~s}$.

\section{MaxQuant analysis and label-free quantification}

Raw MS files generated on the mass spectrometer were processed using MaxQuant (version 1.5.6.0). The protein sequence database (Uniprot_organism_2016_09) was downloaded from Uniprot. This database was then searched against its reverse decoy using the MaxQuant software. The quantification type was label-free quantification matched for run and intensity-based absolute quantification. Trypsin was set as a specific enzyme with up to three missed cleavage sites. Oxidation (M) and acetylation (protein $\mathrm{N}$-term) were considered as variable modifications, and the maximum number of modifications per peptide was three. Carbamidomethyl (C) was set as a fixed modification. The false discovery rate for both peptide and protein was less than 0.01. Only unique and razor peptides were used for quantification. All other parameters were reserved as defaults.

\section{Bioinformatics and statistical analysis}

The standardized quantitative results were analyzed to obtain the corresponding differentially expressed proteins. The experiment comprised two biological 
replicates, and the arithmetical mean of these was used to calculate the fold change. Fold changes in expression of $>1.5$ or $<0.66$ were defined as significant differences, and subsequent gene ontology, Kyoto Encyclopedia of Genes and Genomes pathway and protein interaction analyses were performed.

\section{Western blot}

As in previous studies, western blot analysis was carried out $[9,24]$. One part of the hippocampal tissue obtained from the experimental mice was lysed and homogenized using RIPA buffer containing 1\% protease inhibitor cocktail and $2 \%$ PMSF. The total loading protein $(40 \mu \mathrm{g})$ was quantified using the BCA protein assay kit, separated on $12 \%$ sodium dodecyl sulfate-polyacrylamide gel electrophoresis, and subsequently transferred to a polyvinylidene difluoride membrane $(0.45 \mu \mathrm{m}$; Merck Millipore, Billerica, MA, USA). Next, $5 \%$ bovine serum albumin was used to block the membranes at $4{ }^{\circ} \mathrm{C}$ for $2 \mathrm{~h}$. The membranes were subsequently incubated with the following primary antibodies at $4{ }^{\circ} \mathrm{C}$ overnight: JIP3 (dilution ratio 1:500; $147 \mathrm{kDa}$; bs-13648R), JNK (dilution ratio 1:1000; $48 \mathrm{kDa}$; bs-2592R), APP (dilution ratio 1:1000; $86 \mathrm{kDa}$; bs-0112R), inhibitor of NF-kB kinase alpha+beta $(\mathrm{IKK} \alpha+\beta$; dilution ratio 1:500; $85 \mathrm{kDa}$; bs-7557R), IRF3 (dilution ratio 1:1000; $47 \mathrm{kDa}$; bs-52116R), p-IRF3 (Ser396; dilution ratio 1:500; $47 \mathrm{kDa}$; bs-3195R), Iba1 (dilution ratio 1:500; $16 \mathrm{kDa}$; bs1363R), and GFAP (dilution ratio 1:500; 48 kDa; bs-0199R; Bioss Inc., Beijing, China), p-JNK1 + $2+3$ (p-Y185 + Y185 + Y223; dilution ratio 1:10000; $48 \mathrm{kDa}$; ab76572), p$\mathrm{IKK}(\alpha+\beta ; \mathrm{p}-\mathrm{S} 176+\mathrm{S} 177$; dilution ratio $1: 500 ; 85 \mathrm{kDa}$; ab194528), p-APP (p-T743; dilution ratio 1:1000; $86 \mathrm{kDa}$; ab206297), ELKS (dilution ratio 1:5000; $128 \mathrm{kDa}$; ab180507), inhibitor of nuclear factor kappa-B alpha

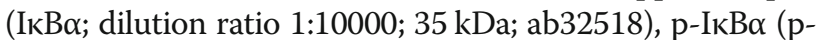
S36; dilution ratio 1:10000; $35 \mathrm{kDa}$; ab133462), NF-кB p65 (dilution ratio 1:500; $65 \mathrm{kDa}$; ab7970), and p-P65NF-kB (p-S536; dilution ratio 1:10000; $65 \mathrm{kDa}$; ab76302), WDrepeat and FYVE-domain-containing protein 1 (WDFY1; dilution ratio 1:1000; $46 \mathrm{kDa}$; ab125329), TLR3 (dilution ratio 1:500; $108 \mathrm{kDa}$; ab13915), and the reference protein glyceraldehyde-3-phosphate dehydrogenase (GAPDH; dilution ratio 1:500; $36 \mathrm{kDa}$; ab181602; Abcam, Cambridge, MA, USA). After washing with TBST $(500 \mathrm{~mL}$ t-butyldimethylsilyl chloride and $0.5 \mathrm{~mL}$ Tween-20), the membranes were incubated with HRP-conjugated secondary antibody (SH-0032; Bejing Dingguo Changsheng Biotechnology Co. Ltd., Beijing, China) at a dilution of 1:2000 at $4{ }^{\circ} \mathrm{C}$ for $4 \mathrm{~h}$. An enhanced chemiluminescence kit (Merck Millipore, Billerica, MA) and imaging system (Bio Spectrum 600; UVP company, Upland, CA, USA) were used to visualize the bands. The ImageJ software (National Institutes of Health, Bethesda, MD, USA) was used to quantify the blots.

\section{Statistical analysis}

All data are presented as mean \pm standard error. Oneway analysis of variance followed by post hoc multiple comparisons (Holm-Sidak test) was used to analyze differences and significance using the SPSS 16.0 software (SPSS Inc., Chicago, IL, USA). Statistical significance was defined at $p$ values $<0.05$.

\section{Results}

\section{Assessment of acute toxicity trials}

The acute toxicity test of FTS•B was carried out in C57 mice. All mice remained alive and showed normal behavior after oral administration of $400 \mathrm{mg} / \mathrm{kg}$ FTS $•$ B. There were no obvious behavioral abnormalities between the FTS $\bullet B$ and control groups either $4 \mathrm{~h}$ or 14 days after FTS $B$ administration. There were no significant changes in the liver, spleen, kidney, or brain after FTS $\bullet \mathrm{B}$ administration (Figure S3), indicating that FTS•B has low toxicity.

\section{FTS-B-ameliorated cognitive decline and pathological alterations in APP/PS1 mice}

Thirty-six days after FTS•B administration, there were no significant effects on body weight (Table S1) and no changes in the liver, spleen, kidney, or brain of APP/PS1 mice (Figure S4), indicating that FTS•B can be used safely.

The Morris water maze test has been widely used to evaluate learning and memory in animals [27]. Compared with vehicle-treated APP/PS1 mice, FTS•B-treated AD mice exhibited less chaotic movements (Fig. 1a) and shorter escape latencies $(p<0.05$; Fig. 1b), and crossed the platform more times $(p<0.05$; Fig. $1 c)$.

The $\mathrm{Y}$ maze test is usually used to examine the shortterm memory of mice [28]. In the Y maze test, the blue dot indicates the mice, the red dot indicates food, and the purple line indicates the movement tracks of the mouse. No visible differences in training time were noted among the experimental groups $(p>0.05$; Fig. 1e). FTS $\bullet B$ suppressed the spontaneous alteration of behavior in APP/PS1 mice (Fig. 1d). In the formal test, mice administered FTS.B found the food in less time than vehicle-treated APP/PS1 mice ( $p<0.05$; Fig. 1f).

The mice's autonomous exploration behaviors in a new environment were evaluated using the open-field experiment [29], wherein the blue dot signifies the initial location of the mice, the red dot indicates the terminal location of the mice, and the purple line denotes the movement tracks of the mouse. FTS•B-administered APP/PS1 mice showed significantly less aimless movement around the central field area (Fig. 1g) than vehicletreated APP/PS1 mice, traveled a greater distance in the surrounding area $(p<0.01$; Fig. $1 \mathrm{~h})$, and traveled less in the central area $(p<0.05$; Fig. 1i). All of these data 


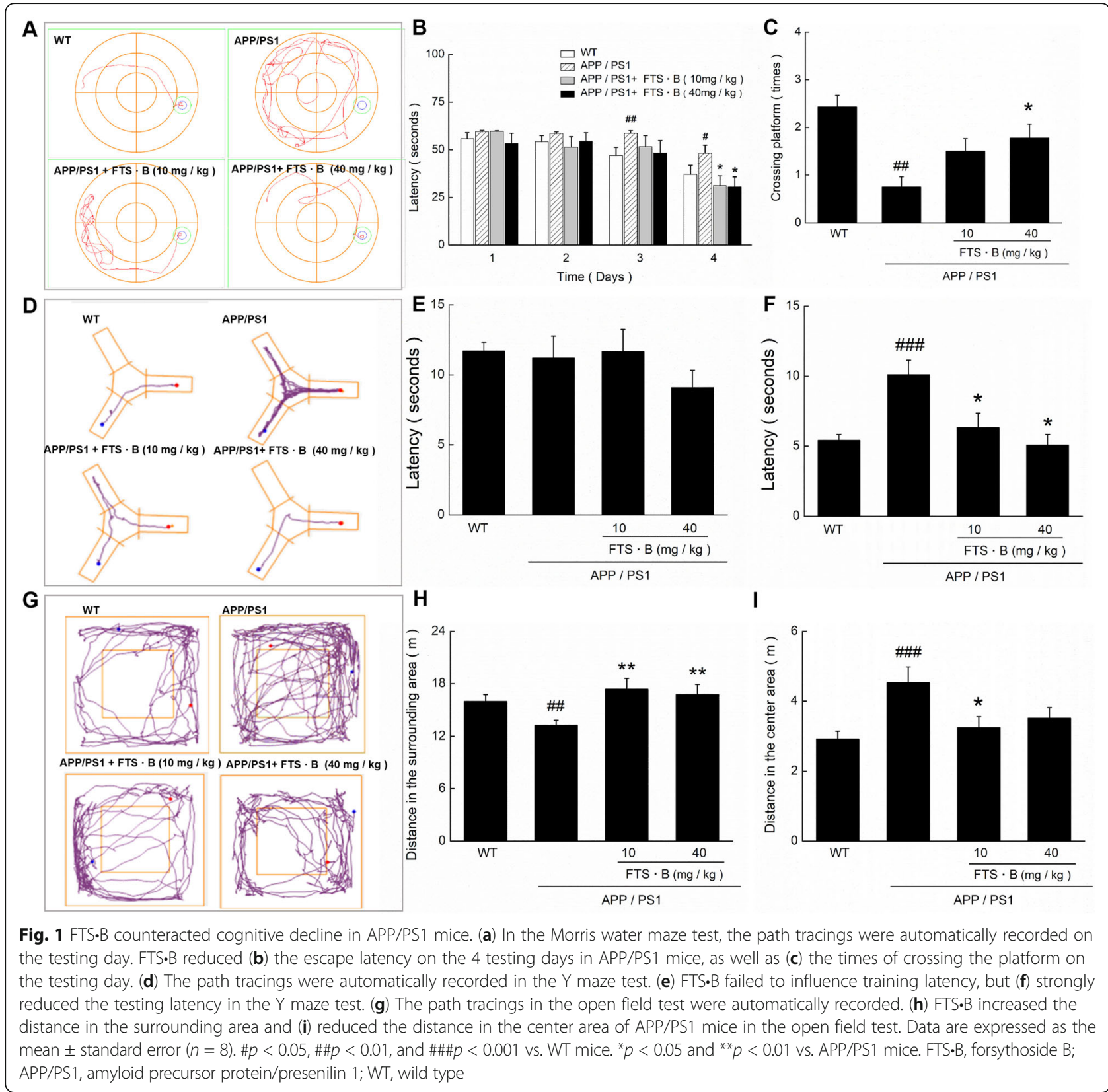

suggest that FTS $B$ strongly ameliorated cognitive decline in APP/PS1 mice.

Vehicle-treated APP/PS1 mice showed overaccumulation of fibrillary amyloid plaques of $A \beta$ in the hippocampus and cerebral cortex, while these plaques were reduced in FTS B-B-treated AD mice, as analyzed using thioflavine $\mathrm{S}$ staining (Fig. 2a). Immunohistochemistry showed that the area covered by $\mathrm{A} \beta$ positive plaques in the hippocampus of APP/PS1 mice was markedly larger than that in WT mice, and that this difference was ameliorated by FTS $\bullet B$ administration (Fig. 2b). As a microtubule-associated protein, tau stabilizes the neuronal cytoskeleton, and its hyperphosphorylation can lead to the formation of toxic neurofibrillary tangles in $\mathrm{AD}$ [30]. 4$\mathrm{HNE}$ exists at higher concentrations in patients with $\mathrm{AD}$ and triggers $A \beta$ aggregation [31]. In the present study, excessive aggregations of $\mathrm{p}$-tau (Fig. 2c) and high expression of 4-HNE (Fig. 2d) were discovered in the hippocampus of vehicle-treated APP/PS1 mice compared to WT mice. All of these differences were strongly attenuated after FTS•B administration. Activated microglia and astrocytes around $\mathrm{A} \beta$ plaques are a representative characteristic of the $\mathrm{AD}$ brain and are conducive to the inflammatory process of brain damage [32]. Iba1 and GFAP are specific biomarkers of activated microglia and astrocytes, respectively [33], so immunohistochemistry of these proteins was used to 


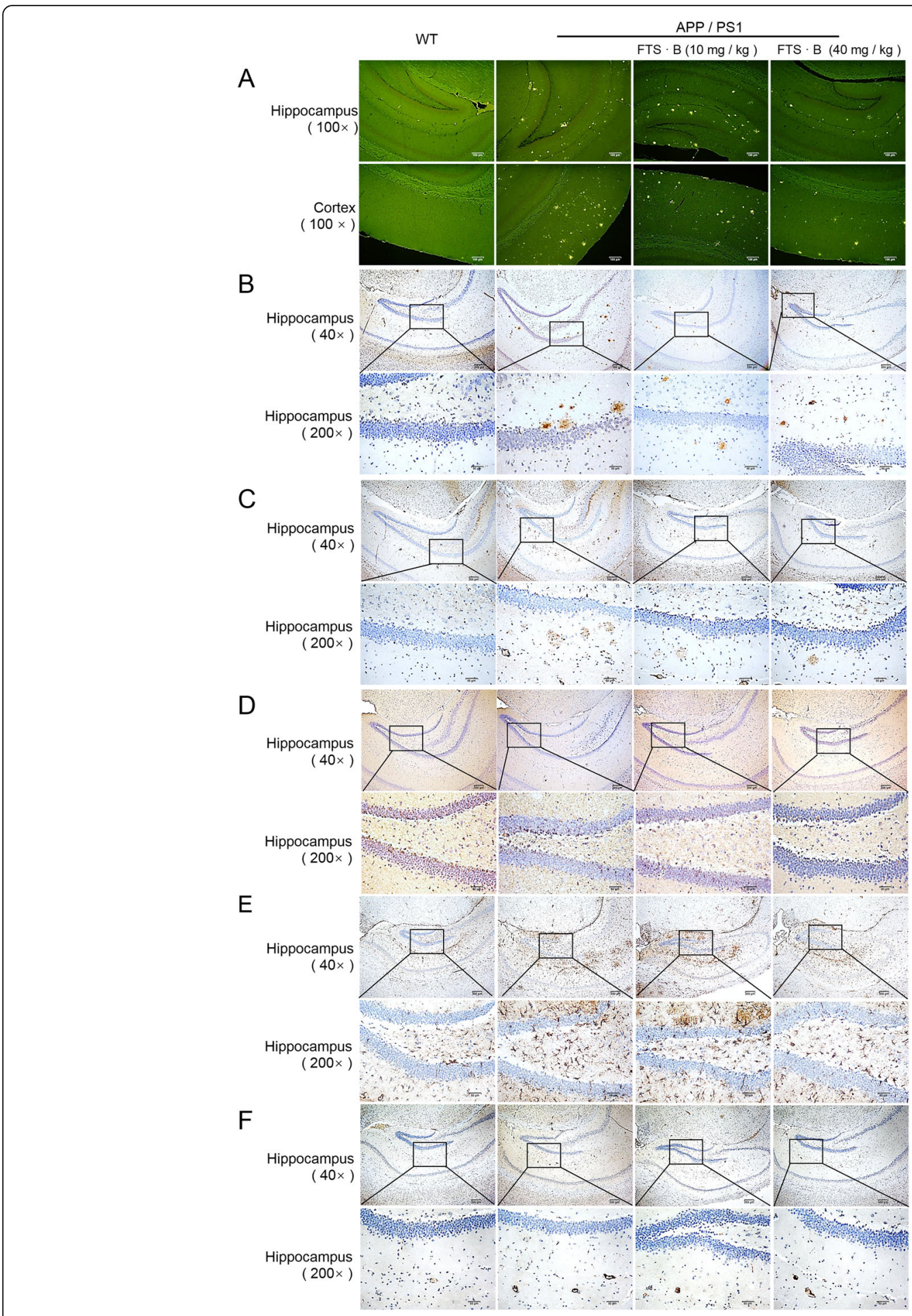

Fig. 2 FTS•B ameliorated pathological alterations in the brains of APP/PS1 mice. FTS•B alleviated the deposition of A 3 in the brains of APP/PS1 mice, detected using (a) thioflavine $S$ staining in the hippocampus and cortex (100x; scale bar: $100 \mu m ; n=3)$ and (b) immunohistochemistry in the hippocampus (40x; scale bar: $200 \mu \mathrm{m} ; 200 x$; scale bar: $50 \mu \mathrm{m} ; n=3)$. FTS B reduced the levels of (c) phospho-tau protein $(n=3)$, (d) 4-HNE $(n=3)$, and (e) GFAP $(n=3)$ in the hippocampus of APP/PS1 mice (40x; scale bar: $200 \mu \mathrm{m}$; 200x; scale bar: $50 \mu \mathrm{m})$. (f) FTS·B suppressed the enrichment of Iba1 around blood vessels in the hippocampus of APP/PS1 mice ( $n=3 ; 40 x$; scale bar: $200 \mu \mathrm{m}$; 200x; scale bar: $50 \mu \mathrm{m})$. FTS•B, forsythoside B; APP/PS1, amyloid precursor protein/presenilin 1; 4-HNE, 4-hydroxynonenal; GFAP, glial fibrillary acidic protein; Iba1, ionized calcium-binding adapter molecule 1 
assess the activation of microglia and astrocytes in the hippocampus. More GFAP-positive cells were noted in the hippocampus of APP/PS1 mice than in that of WT mice. This increase was markedly attenuated after FTS $B$ treatment (Fig. 2e). FTS•B also reduced the enrichment of Iba1 around blood vessels (Fig. 2f).

\section{FTS B-regulated cytokine levels in serum and brain of APP/PS1 mice}

To analyze the specific effects of FTS $\bullet B$ in AD, proteomic analysis was performed on the hippocampus collected from each group. Among the detected proteins, 23 were markedly changed in AD (Table S2). A clustering heatmap of the significant proteins showed that FTS $\cdot B$ upregulated 16 proteins and downregulated 7 in the hippocampus of APP/PS1 mice (Fig. 3a). In the protein-protein interaction analysis, 116 interactions and 49 expected interactions were found (Fig. 3b).

Based on the screening data of proteomic analysis, the markedly changed cytokines were confirmed using ELISA. The over-expression of WDFY1, a potentiator of TLR3 signaling, can lead to elevated IRF3 phosphorylation and IFN- $\beta$ gene expression [34]. FTS $B$ treatment, especially at $40 \mathrm{mg} / \mathrm{kg}$, resulted in increases of $37.3 \%(p<0.01), 12.5 \%$ $(p<0.05)$, and $76.1 \%(p<0.001)$ in serum levels of TLR3, p-IRF3/IRF3, and IFN- $\beta$ (Table 1), respectively, as well as $24.7 \%(p<0.05), 150 \%(p<0.001)$, and $52.6 \%(p<0.05)$ increases in cerebral levels of TLR3, p-IRF3/IRF3, and
IFN- $\beta$ (Table 2). JNK is responsible for APP phosphorylation at Thr668 in differentiated neurons, which can generate $A \beta$ peptide after two endoproteolytic cleavages [35]. Overproduction of JIP3, p-JNK/JNK, p-APP/APP, and A $\beta$ was noted in the serum and brain lysate of APP/PS1 mice $(p<0.05)$ and was significantly reversed by FTS $\bullet$ B administration $(p<0.05$; Tables 1 and 2$)$. $\mathrm{A} \beta$ can activate neuroglia and stimulate the expression of pro-inflammatory chemokines such as TNF- $\alpha$ and ILs, perhaps leading to increased $A \beta$ production and neuronal death $[36,37]$. Compared with vehicle-treated APP/PS1 mice, FTS•B-treated specimens showed markedly lower levels of TNF- $\alpha(p<$ $0.01)$, IL-1 $\beta(p<0.05)$, IL-6 $(p<0.01)$, IL-8 $(p<0.05)$, and IL-12 $(p<0.05)$ in the serum and brain lysate (Tables 1 and 2).

FTS-B-mediated regulation of neuroinflammation-related protein expression and activation in the hippocampus of APP/PS1 mice

To further study the mechanism of FTS $\bullet$ B-mediated anti-neuroinflammation, the activation or phosphorylation of JIP3, JNK, APP, ELKS, IKK $\alpha+\mathrm{IKK} \beta$, IкB $\alpha$, NF$\kappa B$, WDFY1, TLR3, IRF3, Iba1, and GFAP in the hippocampus were assessed using western blotting. Compared with the vehicle-treated APP/PS1 mice, FTS $\bullet B$ visibly downregulated the expression of JIP3, p-JNK $(1+2+3)$, and p-APP in the hippocampus (Fig. 4a). ELKS can combine with the IKK complex and is involved in the

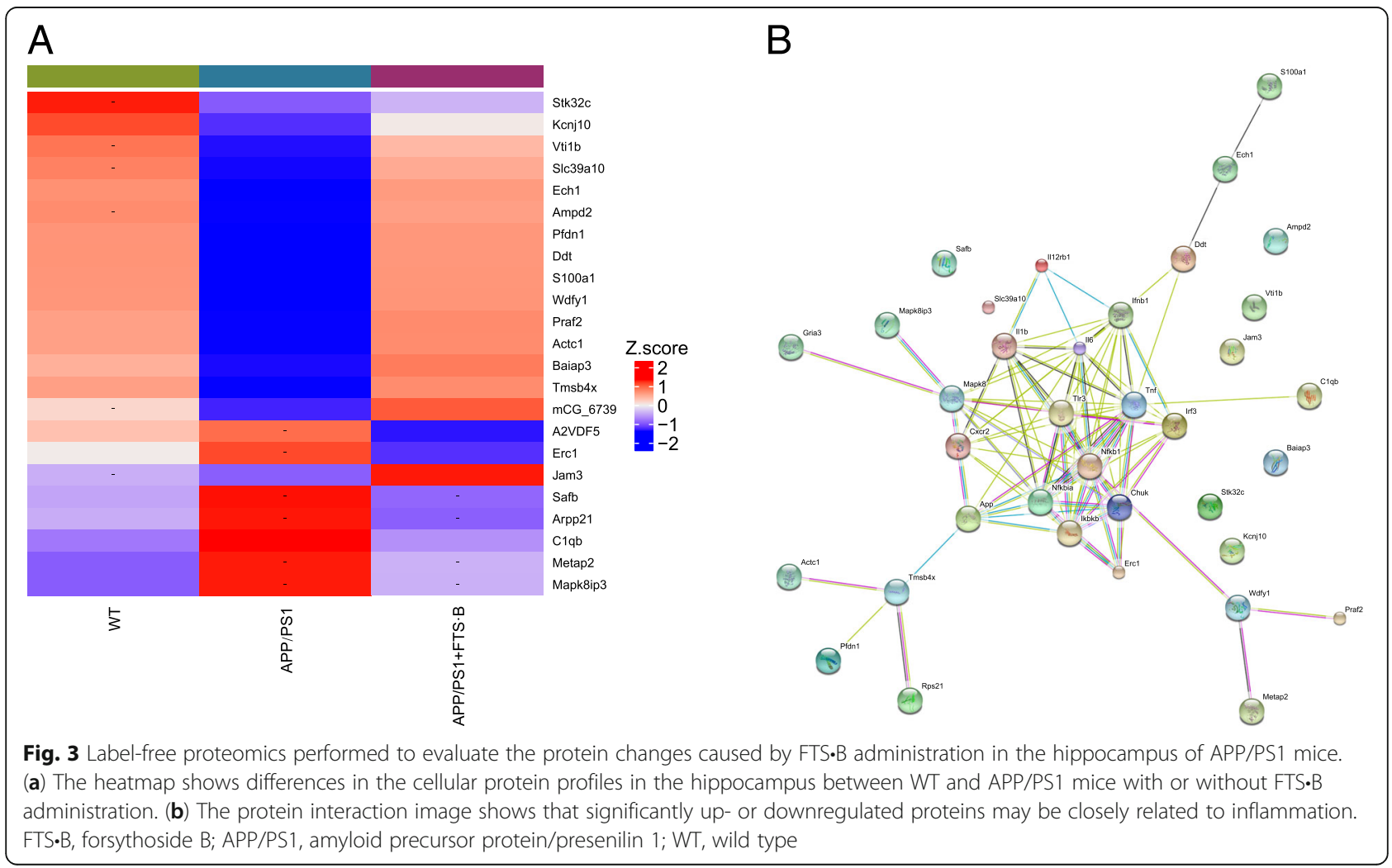


Table 1 The effects of FTS•B on cytokines levels in the serum of APP/PS1 mice

\begin{tabular}{|c|c|c|c|c|}
\hline & \multirow[t]{3}{*}{ WT } & \multicolumn{3}{|l|}{ APP/PS1 } \\
\hline & & & \multicolumn{2}{|l|}{ FTS·B (mg/kg) } \\
\hline & & & 10 & 40 \\
\hline TLR3 (ng/mL) & $29.6 \pm 1.6$ & $21.7 \pm 1.9 \# \#$ & $27.3 \pm 1.7^{*}$ & $29.8 \pm 1.2^{* *}$ \\
\hline p-IRF3/IRF3 & $1.2 \pm 0.1$ & $0.8 \pm 0.0 \# \#$ & $0.9 \pm 0.1^{*}$ & $0.9 \pm 0.0^{*}$ \\
\hline $\mathrm{IFN}-\beta(\mathrm{pg} / \mathrm{mL})$ & $95.4 \pm 7.0$ & $51.5 \pm 7.2 \# \# \#$ & $89.8 \pm 15.4^{*}$ & $90.7 \pm 6.3^{* * *}$ \\
\hline JIP3 (ng/L) & $233.9 \pm 41.7$ & $379 \pm 35.9 \# \#$ & $274.7 \pm 57$ & $219.9 \pm 40.9^{* *}$ \\
\hline p-JNKJJNK & $5.3 \pm 0.6$ & $8.4 \pm 1.0 \# \#$ & $5.3 \pm 0.8^{*}$ & $5.4 \pm 0.6^{*}$ \\
\hline p-APP/APP & $0.2 \pm 0.0$ & $0.4 \pm 0.1 \# \#$ & $0.2 \pm 0.1^{* *}$ & $0.3 \pm 0.1^{* *}$ \\
\hline $\mathrm{A} \beta(\mathrm{mg} / \mathrm{L})$ & $2.5 \pm 0.2$ & $3.0 \pm 0.1 \#$ & $2.4 \pm 0.2^{* *}$ & $2.3 \pm 0.2^{* *}$ \\
\hline TNF-a (ng/L) & $132.6 \pm 13.2$ & $189.7 \pm 22.6 \#$ & $101.5 \pm 25.3^{* *}$ & $103 \pm 17.7^{* *}$ \\
\hline$\| \mathrm{L}-1 \beta$ (ng/L) & $91 \pm 6.1$ & $124.9 \pm 8.9 \#$ & $95.9 \pm 4.9^{* *}$ & $87.8 \pm 7.6^{* *}$ \\
\hline IL-6 (pg/mL) & $193.1 \pm 8.9$ & $223.7 \pm 7.8 \#$ & $190.2 \pm 7.5^{* *}$ & $177.9 \pm 11.9^{* *}$ \\
\hline IL-8 (pg/mL) & $367.3 \pm 23.2$ & 471.8 土 22.9\#\# & $364.1 \pm 37.8^{*}$ & $310.3 \pm 22.9^{* * *}$ \\
\hline IL-12 (ng/L) & $58.6 \pm 6.5$ & $82.3 \pm 4.0 \# \#$ & $69.5 \pm 3.5^{*}$ & $67.2 \pm 2.9^{*}$ \\
\hline
\end{tabular}

Data are expressed as the mean \pm standard error $(n=8)$

$\# p<0.05$

$\# p<0.01$

$\# \#$ \#\# 0.001 vs. WT mice

${ }^{*} p<0.05$

${ }^{* *} p<0.01$

${ }^{* * *} p<0.001$ vs. APP/PS1 mice

Table 2 The effects of FTS B on cytokines levels in the brains of APP/PS1 mice

\begin{tabular}{|c|c|c|c|c|}
\hline & \multirow[t]{3}{*}{ WT } & \multicolumn{3}{|l|}{ APP/PS1 } \\
\hline & & & \multicolumn{2}{|l|}{ FTS•B (mg/kg) } \\
\hline & & & 10 & 40 \\
\hline TLR3 (ug/g prot) & $30.7 \pm 2.9$ & $22.7 \pm 1.9 \# \#$ & $27.6 \pm 2.8^{*}$ & $28.3 \pm 2.3^{*}$ \\
\hline $\mathrm{p}-\mathrm{IRF} 3 / \mathrm{IRF} 3$ & $0.2 \pm 0.0$ & $0.2 \pm 0.0 \#$ & $0.5 \pm 0.1^{*}$ & $0.5 \pm 0.1^{* * *}$ \\
\hline IFN- $\beta$ (ng/g prot) & $30.7 \pm 3.7$ & $17.3 \pm 2.5 \#$ & $23.4 \pm 4.1$ & $26.4 \pm 1.9^{*}$ \\
\hline JIP3 (ng/g prot) & $81.4 \pm 17$ & $171.8 \pm 35.2 \#$ & $59.6 \pm 21.3^{*}$ & $53.8 \pm 10.6^{* *}$ \\
\hline p-JNKJJNK & $7.1 \pm 0.6$ & $10 \pm 1.0 \#$ & $5.6 \pm 1.1^{*}$ & $5.7 \pm 0.7^{* *}$ \\
\hline p-APP/APP & $0.3 \pm 0.0$ & $0.6 \pm 0.1 \#$ & $0.2 \pm 0.1^{* *}$ & $0.2 \pm 0.0^{* *}$ \\
\hline$A \beta$ (mg/g prot) & $1.1 \pm 0.1$ & $1.5 \pm 0.1 \# \#$ & $0.9 \pm 0.1^{* * *}$ & $1.2 \pm 0.1^{* *}$ \\
\hline TNF-a (ng/g prot) & $2.1 \pm 0.1$ & $2.3 \pm 0.1 \#$ & $1.7 \pm 0.1^{* * *}$ & $1.8 \pm 0.1^{* *}$ \\
\hline IL-1 $\beta$ (ng/g prot) & $68.4 \pm 8.1$ & $113.6 \pm 13.1 \# \#$ & $82.5 \pm 10.8^{*}$ & $75.4 \pm 6.4^{* *}$ \\
\hline IL-6 (ng/g prot) & $176.7 \pm 4.3$ & $215.7 \pm 8.3 \# \# \#$ & $171.2 \pm 8.4^{* * *}$ & $170.4 \pm 9.8^{* *}$ \\
\hline IL-8 (ng/g prot) & $96 \pm 15.1$ & $177.5 \pm 28.1 \#$ & $96.2 \pm 18.5^{*}$ & $105.5 \pm 9.1$ \\
\hline IL-12 (ng/g prot) & $37.6 \pm 3.0$ & $56 \pm 5.3 \#$ & $29.7 \pm 5.6^{* *}$ & $29 \pm 4.2^{* *}$ \\
\hline
\end{tabular}

Data are expressed as the mean \pm standard error $(n=8)$

${ }^{\#} p<0.05$

$\#$ \#\# $p .01$

$\# \# p<0.001$ vs. WT mice

${ }^{*} p<0.05$

${ }^{* *} p<0.01$

${ }^{* * *} p<0.001$ vs. APP/PS1 mice 

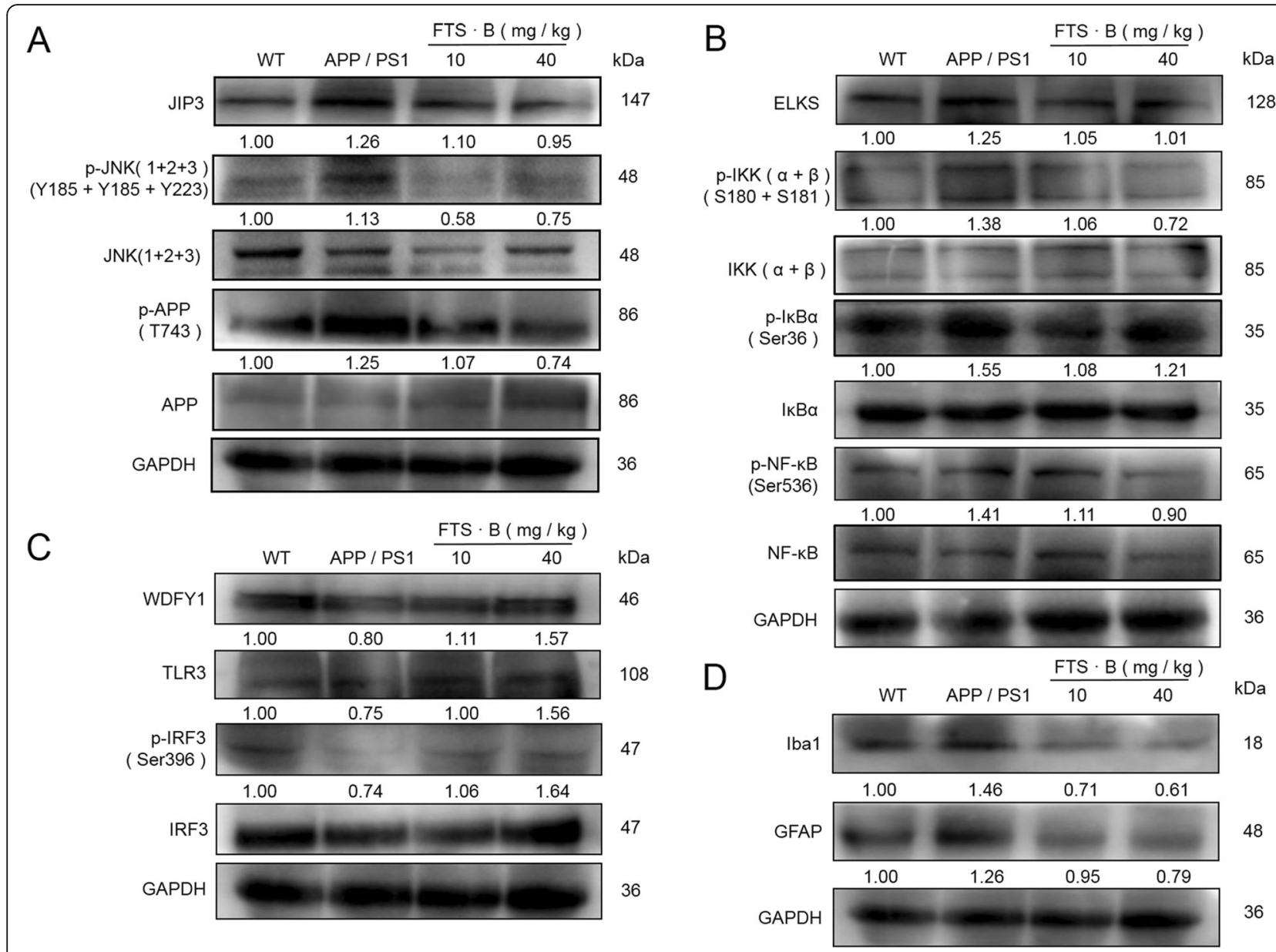

Fig. 4 The regulation of FTS•B on proteins related to neuroinflammation in the hippocampus of APP/PS1 mice. (a) FTS•B reduced the expression levels of JIP3 and the phosphorylation levels of JNK and APP. (b) FTS.B suppressed the expression levels of ELKS and the phosphorylation levels of IKK $(a+\beta)$, IKBa, and NF-KB p65. (c) FTS.B enhanced the expression levels of WDFY1 and TLR3, as well as the phosphorylation levels of IRF3. (d) FTS.B reduced the expression levels of Iba1 and GFAP. Quantification data were normalized to GAPDH and corresponding total proteins $(n=3)$. They were reported as folds of the corresponding WT group. FTS•B, forsythoside B; APP/PS1, amyloid precursor protein/presenilin 1; JIP3, JNKinteracting protein 3; JNK, C-Jun NH2-terminal kinase; APP, amyloid-beta precursor protein; IKK, inhibitor of nuclear factor kappa-B kinase; IKBa, inhibitor of nuclear factor kappa-B alpha; NF-KB, nuclear factor-kB; WDFY1, WD-repeat and FYVE-domain-containing protein 1; TLR3, toll-like receptor 3; IRF3, interferon regulating factor 3; Iba1, ionized calcium-binding adapter molecule 1; GFAP, glial fibrillary acidic protein

activation of NF- $\mathrm{kB}$ [38]. FTS•B administration suppressed the levels of ELKS, p-IKK $(\alpha+\beta)$, p-IKB $\alpha$, and pNF-kB (Ser536) in the hippocampus of APP/PS1 mice (Fig. 4b), while enhancing the levels of WDFY1, TLR3, and p-IRF3 (Fig. 4c). Furthermore, compared with the vehicle-treated APP/PS1 mice, FTS $\bullet B$ downregulated Iba1 by $51.4 \%$ and GFAP by $24.6 \%$ in the hippocampus (Fig. 4d).

\section{FTS B-mediated prevention of LPS-induced neuroinflammation in BV-2 cells}

FTS.B alone $(1 \mu \mathrm{M}$ and $2.5 \mu \mathrm{M})$ or in co-incubation with LPS $(1 \mu \mathrm{g} / \mathrm{mL})$ showed no significant effects on the cell viability of BV-2 cells (Fig. 5a). The LPS-induced enhancements of IL-6 ( $p<0.01$; Fig. 5b), TNF- $\alpha(p<0.01$; Fig. 5c), iNOs ( $p<0.05$; Fig. $5 d)$, NO ( $p<0.05$; Fig. 5e), and IL-1 $\beta$ ( $p<0.01$; Fig. $5 f$ ) in BV-2 cells were strongly suppressed by FTS $\bullet$ B pre-incubation $(p<0.05$; Fig. $5 b-f)$.

\section{FTS-B-mediated reduction in microglia-mediated neurotoxicity}

Activated microglia exert neurotoxic effects by releasing pro-inflammatory enzymes and mediators [39]. When conditioned media from LPS-stimulated microglia were added to cultured HT22 cells, the apoptosis rate of these cells was significantly increased $(p<0.001$; Fig. $6 \mathrm{a}$ and b), and cell viability was significantly reduced $(p<0.001$; Fig. 6c). However, pretreatment of BV-2 cells with FTS B prior to LPS stimulation significantly suppressed the apoptosis rate of the HT22 cells $(p<0.001$; Fig. 6a and b) and enhanced cell viability $(p<0.05$; Fig. $6 \mathrm{c})$, demonstrating the neuroprotective effects of FTS $\bullet$ B. 

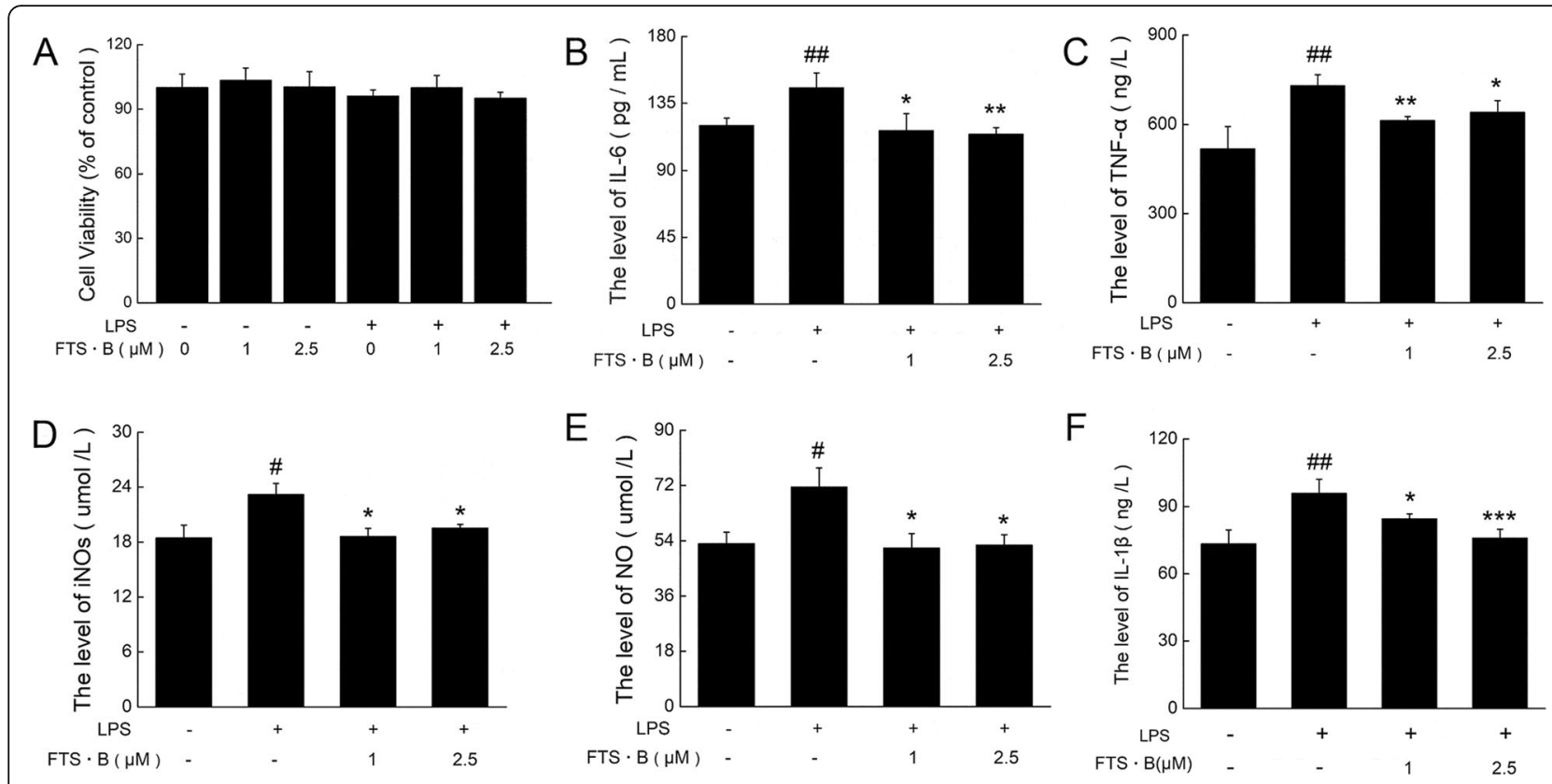

Fig. 5 FTS.B incubation regulated the levels of inflammatory cytokines in LPS-exposed BV-2 cells. (a) FTS.B alone or in co-incubation with LPS showed no effects on cell viability of BV-2 cells. Compared with LPS-alone exposed cells, FTS·B co-incubation strongly suppressed the release of (b) IL-6, (c) TNF-a, (d) iNOs, (e) NO, and (f) IL-1 $\beta$ in BV-2 cells, determined by ELISA. Data are expressed as mean \pm standard error $(n=3)$. \#p $<0.05$ and \#\#p $<0.01$ vs. non-treated cells. ${ }^{*} p<0.05$, ${ }^{*} p<0.01$, and ${ }^{* *} p<0.001$ vs. LPS-alone exposed cells. FTS.B, forsythoside B; LPS, lipopolysaccharide; IL-6, interleukin 6 ; TNF-a, tumor necrosis factor a; iNOs, inducible nitric oxide synthase; NO, nitric oxide; IL-1 $\beta$, interleukin 1 1 ; ELISA, enzyme-linked immunosorbent assay

\section{Discussion}

In the present study, we found FTS•B attenuates $\mathrm{AD}$ symptoms, pathology, and decreases neuroinflammation signaling and cytokines in mice models and cell culture. These findings, for the first time, prove FTS•B modulate neuroinflammation in the central nervous system and inhibit the progression of AD, suggesting FTS $\bullet B$ is a potential therapeutic medicine in the future. These findings also support the hypothesis that neuroinflammation mediates the progression of $\mathrm{AD}$ [40].

4-HNE, $A \beta$, and neurofibrillary are the central pathological mechanism of AD. 4-HNE triggers $A \beta$ aggregation by accelerating $A \beta$ protofibril formation [41]. Tauopathy in the form of neurotic plaques and cerebral $\beta$-amyloidosis in the form of $A \beta$ plaques are two possible causes of the pathological features of AD [42]. Neurofibrillary tangles consist of intracellular bundles of selfassembled $\mathrm{p}$-tau, which are induced by $\mathrm{A} \beta$ deposition and lead to neuronal degeneration [43]. APP/PS1 double-transgenic mice with $\mathrm{AD}$ imitate human progressive cognitive deficits and neuropathological characteristics, including neuroinflammation [44]. By using APP/ PS1 AD mice, we showed FTS $\bullet B$ significantly enhanced the learning and memory capabilities of APP/PS1 mice and markedly suppressed the deposition of $A \beta$, the formation of neurofibrillary tangles composed of p-tau protein, and the levels of 4-HNE in the hippocampus. These results suggest FTS $\bullet B$ administration decreases the $A \beta$ accumulation and its downstream pathological effects to protect neuronal damages in $\mathrm{AD}$ mice.

Neuroinflammation is associated with $\mathrm{AD}$ and is hypothesized to be the key mediator of AD [40]. Neuroinflammation is characterized by $A \beta$ activated microglia which secretes neurotoxic mediators and proinflammatory cytokines to activate astrocytes to be neurotoxic $[45,46]$. Neuroinflammation causes neuronal death by neurotoxic astrocytes which upregulates complement cascade and neurotoxins [47, 48]. Further, neuroinflammation can amplify itself by increasing tauopathy and $A \beta$ deposition through microglia-secreted pro-inflammatory cytokines such as IL- 6 and TNF- $\alpha$ [49]. A key mediator of neuroinflammation is the activation of NF- $\mathrm{KB}$ in astrocyte and microglial cells. Latent NF- $\mathrm{kB}$ can be activated by many inflammatory stimulations such as $A \beta$ [8], transport-activated JNK3 [50], neurofibrillary tangles [51], and TNF- $\alpha$ [52]. Activated NF- $\kappa B$ increases the production of IL- $1 \beta$, TNF- $\alpha$, iNOS, and IL-6 [53, 54]. Another key mediator of neuroinflammation is JNK in the central nervous system. Patients with AD show upregulated expression of JNK in the brains, which promotes amyloidogenic APP cleavage and amyloid plaque formation [55]. Activated astrocytes and microglia increases the expression of GFAP and Iba1, respectively [33], and we showed FTS $B$ reduced the expression of GFAP and Iba1 in the 


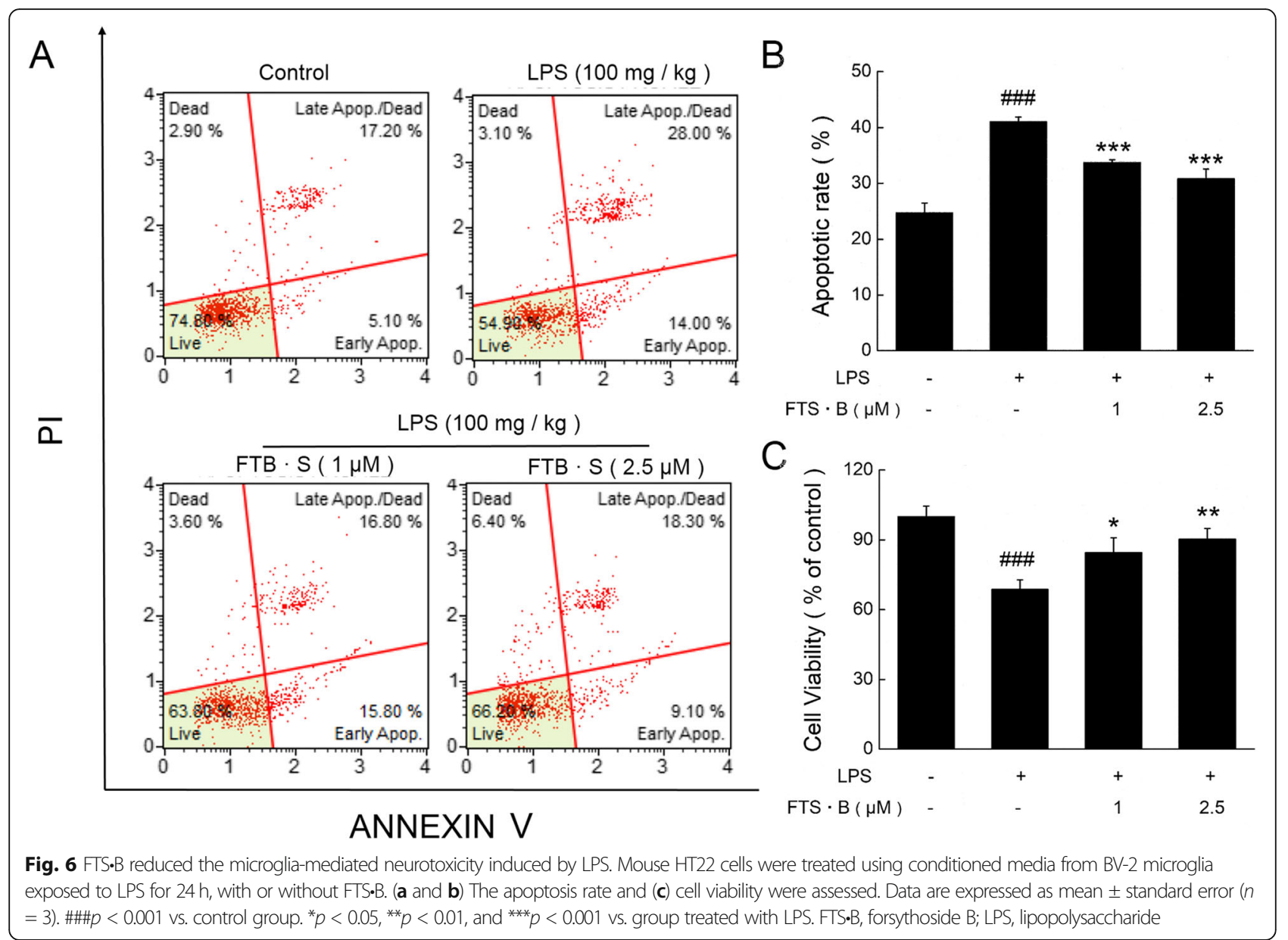

hippocampus, indicating that FTS•B suppressed the activation of astrocytes and microglia in $\mathrm{AD}$ mice. We showed FTS•B decreases the NF-kB and JNK inflammatory pathways and inflammatory cytokines including IL-6, TNF- $\alpha$, IL- $1 \beta$, IL- 8 , and IL-12, suggesting FTS•B inhibits the inflammatory signaling pathways in AD mice. WDFY1 overexpression enhances TLR3-mediated NF- $\mathrm{BB}$ activation and IRF3 phosphorylation, inducing the production of IFNs and various pro-inflammatory cytokines [56]. Interestingly, we showed FTS B increases WDFY1 expression, activates TLR3-IRF3 pathways, and increases IFN- $\beta$ production, suggesting FTS $\bullet B$ may improve the neuronal function and autophagy [57]. These results suggest FTS•B suppresses the activation of microglia and astrocytes and neuroinflammation, while maintaining proper neuronal function.

In vivo experiment did not prove the downregulation of inflammatory cytokines is due to the inactivation of microglia. Thus, we use tissue culture of microglia cells as a model. BV-2 microglial cells is an effective substitute for primary microglia [58]. When induced by LPS, it shows properties associated with inflammation, which imitates the neuroinflammation in $\mathrm{AD}$ mice and $\mathrm{AD}$ patient individuals [59]. We used LPS-induced BV-2 microglial activation as a classic inflammatory model to evaluate the antineuroinflammatory effects of potential therapeutic candidates [60]. In the present study, FTS•B significantly suppressed the production of pro-inflammation cytokines in BV-2 cells stimulated by LPS. It was reported that the activated microglia develops neurotoxicity effects via the release of pro-inflammatory mediators [61]. The co-culture system of neuronmicroglia provides an environment for them to grow together, which is diffusely used to detect the neuroprotective effects of anti-inflammatory drugs [62]. Hence, hippocampal HT22 cells were used as a neuronal model to confirm the protective effect of FTS $\cdot B$ on LPS-induced BV-2 microglia toxicity. The conditioned media from LPS-induced BV-2 cells was diffused into the HT-22 neuronal cells, leading to the HT-22 apoptosis. FTS •B suppressed the apoptosis rate of HT22 cells exposed to medium containing the secondary metabolite of BV-2 cells stimulated by LPS. These results suggest FTS B increases neuronal survival through suppressing the activation of microglia. 
Current treatment of AD involves N-methyl-D-aspartate receptor antagonists, acetylcholinesterase inhibitors, and non-steroidal anti-inflammatory drugs. These drugs have disadvantages: inefficiency, tolerance, and sideeffects. We perform acute toxicity trials and histopathological examinations of the organs of APP/PS1 mice to show that FTS $\bullet B$ is safe to use, with no obvious side effects. In the entire experiment of 36 days, FTS•B completely attenuated the $\mathrm{AD}$ symptoms and pathological features. These results suggest FTS•B is a new and safe candidate drug for $\mathrm{AD}$ treatment in the future.

The present study had some limitations. First, FTS•B is a natural product that targets multiple cell types and molecules which means FTS•B may target molecules other than inflammation. Although FTS•B supports the hypothesis that neuroinflammation might mediate the progression of $\mathrm{AD}$, we need further mechanism studies to illustrate whether neuroinflammation is the major mediator of AD. For example, we may restore NF- $\mathrm{kB}$ activity and see whether $A \beta$ deposition is restored. Second, we did not measure how much FTS•B passing through the blood-brain barrier, so we do not know whether FTS.B directly targets brain cells or reduces systemic inflammation and indirectly attenuate neuronal inflammation. A potential solution to this issue may be the use of a NF- $\mathrm{kB}$ reporter mice treated with FTS $\bullet$ B.

Our proteomics and western blot studies show upregulated proteins (TLR3, p-IRF3, IFN- $\beta$, and WDFY1) and downregulated proteins (JIP3, p-JNK, p-APP, ELKS, pIKK, $p-I_{\kappa} B \alpha$, and $\left.p-N F \kappa B\right)$. These proteins suggest FTS $\bullet B$ modifies NF- $\mathrm{KB}$ pathways. In the future, we will identify the downstream target of FTS $\bullet B$ among these candidate proteins and study the molecular mechanisms of FTS $B$ to illustrate how FTS $\bullet B$ protects from AD at the molecular level.

\section{Conclusions}

In summary, the present study was the first to systematically report that FTS $B$ exhibited neuroprotective effects in APP/PS1 mice, ameliorated $A \beta$ deposition and tau protein phosphorylation, and attenuated microglia and astrocyte activation, thus restoring cognitive function. FTS $B$ prevented LPS-induced neuroinflammation and reduced microglia-mediated neurotoxicity in BV-2 and HT22 cells. The neuroprotective effect of FTS $B$ may be mediated by its anti-neuroinflammatory activities, which are regulated via the NF- $\mathrm{KB}$ signaling pathway. The results suggest that FTS•B shows safe and promising therapeutic effects in $\mathrm{AD}$ treatment. The results also support the hypothesis that neuroinflammation is a key mediator of $\mathrm{AD}$ [40]. Further mechanism study is needed to illustrate the molecular mechanism of FTS $\bullet B$ and the contribution of neuroinflammation in the progression of AD.

\section{Supplementary information}

Supplementary information accompanies this paper at https://doi.org/10. 1186/s12974-020-01967-2.

\begin{abstract}
Additional file 1: Table S1. The body weights of WT mice and APP/ PS1 mice. Table S2. Details of the significantly up- or down-regulated proteins by FTS•B among experimental groups. Figure S1. Chemical structure of FTS B. Figure S2. The process of the drug administration and behavioral tests. Figure S3. Compared with normal saline group, $400 \mathrm{mg} / \mathrm{kg}$ of FTS.B treatment caused no substantial changes in liver, spleen, kidney and brain tissues. (A) Liver, (B) spleen, (C) kidney and (D) brain were detected by H\&E staining (200x; scale bar $=50 \mu \mathrm{m})$. No substantial changes were noted among all experimental mice. FTS•B, forsythoside B; H\&E, hematoxylin and eosin. Figure S4. FTS•B caused no substantial changes in liver, spleen, kidney and brain tissues. (A) Liver, (B) spleen, (C) kidney and (D) brain were detected by H\&E staining (200X; scale bar $=50 \mu \mathrm{m})$. No substantial changes were noted among all experimental mice. FTS•B, forsythoside B; H\&E, hematoxylin and eosin.
\end{abstract}

\section{Abbreviations}

MTT: 3-(4, 5-dimethyl-2-thiazolyl) 2, 5-diphenyl-2H-tetrazolium bromide assay; 4-HNE: 4-hydroxynonenal; ACN: Acetonitrile; BCA: Bicinchoninic acid; AD: Alzheimer's disease; A 3 : Amyloid-beta; APP: Amyloid-beta precursor protein; APP/PS1: Amyloid precursor protein/presenilin 1; JNK: C-Jun NH2terminal kinase; DMEM: Dulbecco's modified Eagle's medium; ELISA: Enzymelinked immunosorbent assay; FA: Formic acid; FTS•B: Forsythoside B; GFAP: Glial fibrillary acidic protein; H\&E: Hematoxylin and eosin; HRP: Horseradish peroxidase; IkBa: Inhibitor of nuclear factor kappa-B alpha; $\mathrm{iNO}_{5}$ : Inducible nitric oxide synthase; IKKa: Inhibitor of nuclear factor kappa-B kinase alpha; IKK : Inhibitor of nuclear factor kappa-B kinase beta; IFN-

$\beta$ : Interferon-beta; IRF3: Interferon regulating factor 3 ; IL-1 $\beta$ : Interleukin-1 beta; IL-6: Interleukin-6; IL-8: Interleukin-8; IL-12: Interleukin-12; Iba1: Ionized calcium-binding adapter molecule 1; JIP3: JNK-interacting protein 3; LPS: Lipopolysaccharide; NO: Nitric oxide; NF-kB: Nuclear factor-kB; PMSF: Phenylmethanesulfonyl fluoride; PBS: Phosphate buffered saline; RIPA: Radio immunoprecipitation assay; GAPDH: Reference protein glyceraldehyde-3-phosphate dehydrogenase; TLR3: Toll-like receptor 3; TNFa: Tumor necrosis factor-alpha; WDFY1: WD-repeat and FYVE-domaincontaining protein 1

\section{Acknowledgements}

Not applicable.

\section{Authors' contributions}

DW and YZ designed the experiments. FK, XJ, RW, and SZ performed the experiments. FK and $X J$ processed data. FK and XJ wrote the paper. DW and $Y Z$ revised the paper. All authors read and approved the final manuscript.

\section{Funding}

This work was supported by the Ministry of Science and Technology of the People's Republic of China (Grant No. 2018YFE0107800), the "13 $3^{\text {th }}$ Five-year" Science and Technology Projects from Education Department in Jilin Province of P. R. China (Grant No. JJKH20190108KJ), Industrial Technology Research and Development Projects from Development and Reform Commission of Jilin Province (Grant No. 2019C050-8) and Health Special Project of Finance Department in Jilin Province of P. R. China (Grant No. 2020SCZT077).

\section{Availability of data and materials}

The datasets used and/or analyzed during the current study are available from the corresponding author on reasonable request.

Ethics approval and consent to participate

Institution Animal Ethics Committee of Jilin University approved the experimental protocol (No. SY201904011).

Consent for publication

Not applicable. 


\section{Competing interests}

The authors declare that they have no competing interests.

Received: 1 July 2020 Accepted: 24 September 2020 Published online: 15 October 2020

\section{References}

1. Caraci F, Santagati M, Caruso G, Cannavo D, Leggio GM, Salomone S, Drago F: New antipsychotic drugs for the treatment of agitation and psychosis in Alzheimer's disease: focus on brexpiprazole and pimavanserin. F1000Research 2020, 9

2. Bessey $\sqcup$, Walaszek A. Management of behavioral and psychological symptoms of dementia. Current Psychiatry Reports. 2019;21.

3. Huang L-K, Chao S-P, Hu C-J. Clinical trials of new drugs for Alzheimer disease. J Biomed Sci. 2020;27.

4. Toublet F-X, Lecoutey C, Lalut J, Hatat B, Davis A, Since M, Corvaisier S, Freret T, Santos JSO, Claeysen $\mathrm{S}$, et al. Inhibiting acetylcholinesterase to activate pleiotropic prodrugs with therapeutic interest in Alzheimer's disease. Molecules. 2019;24.

5. Medrano-Jimenez E, Jimenez-Ferrer Carrillo I, Pedraza-Escalona M, RamirezSerrano CE, Alvarez-Arellano L, Cortes-Mendoza J, Herrera-Ruiz M, JimenezFerrer E, Zamilpa A, Tortoriello J, et al. Malva parviflora extract ameliorates the deleterious effects of a high fat diet on the cognitive deficit in a mouse model of Alzheimer's disease by restoring microglial function via a PPARgamma-dependent mechanism. J Neuroinflammation. 2019;16.

6. Cao J, Hou J, Ping J, Cai D. Advances in developing novel therapeutic strategies for Alzheimer's disease. Mol Neurodegener. 2018;13.

7. Kaur D, Sharma V, Deshmukh R. Activation of microglia and astrocytes: a roadway to neuroinflammation and Alzheimer's disease. Inflammopharmacology. 2019;27:663-77.

8. Haghighatseir N, Ashrafi H, Rafiei P, Azadi A. Dexamethasone ameliorates Alzheimer's pathological condition via inhibiting Nf-kappa B and mTOR signaling pathways. Biointerface Research In Applied Chemistry. 2020;10: 5792-6.

9. Li L, Wu XH, Zhao XJ, Xu L, Pan CL, Zhang ZY. Zerumbone ameliorates behavioral impairments and neuropathology in transgenic APP/PS1 mice by suppressing MAPK signaling. J Neuroinflammation. 2020;17:61.

10. Gong Z, Huang J, Xu B, Ou Z, Zhang L, Lin X, Ye X, Kong X, Long D, Sun X, et al. Urolithin $A$ attenuates memory impairment and neuroinflammation in APP/PS1 mice. J Neuroinflammation. 2019;16:62.

11. Lee $\mathrm{CH}$, Yi M-H, Chae DJ, Zhang E, Oh S-H, Kim DW. Effect of pioglitazone on excitotoxic neuronal damage in the mouse hippocampus. Biomol Ther. 2015;23:261-7.

12. Matsuoka Y, Kitamura Y, Okazaki M, Terai K, Taniguchi T. Kainic acid-induced activation of nuclear factor-kappa B in rat hippocampus. Exp Brain Res. 1999;124:215-22.

13. Deshpande P, Gogia N, Singh A. Exploring the efficacy of natural products in alleviating Alzheimer's disease. Neural Regen Res. 2019;14:1321-9.

14. Wang Z, Xia Q, Liu X, Liu W, Huang W, Mei X, Luo J, Shon M, Lin R, Zou D, Ma Z. Phytochemistry, pharmacology, quality control and future research of Forsythia suspensa (Thunb.) Vahl: a review. J Ethnopharmacol. 2018;210:318-39.

15. Han J, Zhang Y, Pan C, Xian Z, Pan C, Zhao Y, Li C, Yi Y, Wang L, Tian J, et al. Forsythoside A and forsythoside B contribute to Shuanghuanglian injectioninduced pseudoallergic reactions through the RhoA/ROCK signaling pathway. Int J Mol Sci. 2019;20.

16. Liu JX, Li X, Yan FG, Pan QJ, Yang C, Wu MY, Li G, Liu HF. Protective effect of forsythoside $B$ against lipopolysaccharide-induced acute lung injury by attenuating the TLR4/NF-kappa B pathway. Int Immunopharmacol. 2019;66: 336-46.

17. Jiang $W L$, Yong $X$, Zhang SP, Zhu HB, Jian H. Forsythoside B protects against experimental sepsis by modulating inflammatory factors. Phytother Res. 2012;26:981-7.

18. Jiang WL, Fu FH, Xu BM, Tian JW, Zhu HB, Jian H. Cardioprotection with forsythoside $B$ in rat myocardial ischemia-reperfusion injury: relation to inflammation response. Phytomedicine. 2010;17:635-9.

19. Li Z, Chen X, Zhang Y, Liu X, Wang C, Teng L, Wang D. Protective roles of Amanita caesarea polysaccharides against Alzheimer's disease via Nrf2 pathway. Int J Biol Macromol. 2019;121:29-37.

20. Li Z, Chen X, Lu W, Zhang S, Guan X, Li Z, Wang D. Anti-oxidative stress activity is essential for Amanita caesarea mediated neuroprotection on glutamate-induced apoptotic HT22 cells and an Alzheimer's disease mouse model. Int J Mol Sci. 2017;18

21. Liao Q, Li Q, Zhao Y, Jiang P, Yan Y, Sun H, Liu W, Feng F, Qu W: Design, synthesis and biological evaluation of novel carboline-cinnamic acid hybrids as multifunctional agents for treatment of Alzheimer's disease. Bioorg Chem 2020, 99:103844-103844

22. Xu Y, Hu R, He D, Zhou G, Wu H, Xu C, He B, Wu L, Wang Y, Chang Y, et al. Bisdemethoxycurcumin inhibits oxidative stress and antagonizes Alzheimer's disease by up-regulating SIRT1. Brain And Behavior. 2020;10.

23. Zhang Y, Wang J, Wang C, Li Z, Liu X, Zhang J, Lu J, Wang D. Pharmacological basis for the use of evodiamine in Alzheimer's disease: antioxidation and antiapoptosis. Int J Mol Sci. 2018;19.

24. Wang D, Jiang X, Teng SS, Zhang YQ, Liu Y, Li X, Li Y. The antidiabetic and antinephritic activities of Auricularia cornea (an albino mutant strain) via modulation of oxidative stress in the $\mathrm{db} / \mathrm{db}$ mice. Front Immunol. 2019;10:11.

25. Grinan-Ferre C, Marsal-Garcia L, Bellver-Sanchis A, Kondengaden SM, Turga RC, Vazquez S, Pallas M. Pharmacological inhibition of G9a/GLP restores cognition and reduces oxidative stress, neuroinflammation and betaAmyloid plaques in an early-onset Alzheimer's disease mouse model. Aging-Us. 2019;11:11591-608.

26. Wang C, Cai X, Hu W, Li Z, Kong F, Chen X, Wang D. Investigation of the neuroprotective effects of crocin via antioxidant activities in HT22 cells and in mice with Alzheimer's disease. Int J Mol Med. 2019;43:956-66.

27. Azm SAN, Vafa M, Sharifzadeh M, Safa M, Barati A, Mirshafiey A. Effects of M2000 (D-mannuronic acid) on learning, memory retrieval, and associated determinants in a rat model of Alzheimer's disease. American Journal Of Alzheimers Disease And Other Dementias. 2017:32:12-21.

28. Wang Y, Wang M, Xu M, Li T, Fan K, Yan T, Xiao F, Bi K, Jia Y. Nootkatone, a neuroprotective agent from Alpiniae Oxyphyllae Fructus, improves cognitive impairment in lipopolysaccharide-induced mouse model of Alzheimer's disease. Int Immunopharmacol. 2018;62:77-85.

29. Souza LC, Jesse CR, Del Fabbro L, de Gomes MG, Gomes NS, Borges Filho C, Rossito Goes AT, Wilhelm EA, Luchese C, Roman SS, Boeira SP. Aging exacerbates cognitive and anxiety alterations induced by an intracerebroventricular injection of amyloid-beta(1-42) peptide in mice. Mol Cell Neurosci. 2018;88:93-106.

30. Kumar K, Kumar A, Keegan RM, Deshmukh R. Recent advances in the neurobiology and neuropharmacology of Alzheimer's disease. Biomed Pharmacother. 2018;98:297-307.

31. Wilson EN, Do Carmo S, Welikovitch LA, Hall H, Aguilar LF, Foret MK, lulita MF, Jia DT, Marks AR, Allard S, et al. NP03, a microdose lithium formulation, blunts early amyloid post-plaque neuropathology in McGillR-Thy1-APP Alzheimer-like transgenic rats. Journal Of Alzheimers Disease. 2020;73:723-39.

32. Ou Z, Kong X, Sun X, He X, Zhang L, Gong Z, Huang J, Xu B, Long D, Li J, et al. Metformin treatment prevents amyloid plaque deposition and memory impairment in APP/PS1 mice. Brain Behavior And Immunity. 2018;69:351-63.

33. Liu L, Liu Y, Li N, Huang R, Zheng X, Huang L, Hou S, Yuan Q. Multiple inflammatory profiles of microglia and altered neuroimages in APP/PS1 transgenic AD mice. Brain Res Bull. 2020;156:86-104.

34. Nandakumar R, Paludan SR. Catching the adaptor-WDFY1, a new player in the TLR-TRIF pathway. EMBO Rep. 2015;16:397-8.

35. Muresan Z, Muresan V. c-Jun NH2-terminal kinase-interacting protein-3 facilitates phosphorylation and controls localization of amyloid-beta precursor protein. J Neurosci. 2005:25:3741-51.

36. Fu AKY, Hung K-W, Yuen MYF, Zhou X, Mak DSY, Chan ICW, Cheung TH, Zhang B, Fu W-Y, Liew FY, Ip NY. IL-33 ameliorates Alzheimer's disease-like pathology and cognitive decline. Proc Natl Acad Sci U S A. 2016;113:E2705-13.

37. Dionisio-Santos DA, Olschowka JA, O'Banion MK. Exploiting microglial and peripheral immune cell crosstalk to treat Alzheimer's disease. J Neuroinflammation. 2019;16.

38. Sigala JLD, Bottero V, Young DB, Shevchenko A, Mercurio F, Verma IM. Activation of transcription factor NF-kappa B requires ELKS, an I kappa B kinase regulatory subunit. Science. 2004;304:1963-7.

39. Lee D-S, Jeong G-S. Arylbenzofuran isolated from Dalbergia odorifera suppresses lipopolysaccharide-induced mouse BV2 microglial cell activation, which protects mouse hippocampal HT22 cells death from neuroinflammation-mediated toxicity. Eur J Pharmacol. 2014;728:1-8.

40. Ozben T, Ozben S. Neuro-inflammation and anti-inflammatory treatment options for Alzheimer's disease. Clin Biochem. 2019;72:87-9. 
41. Siegel SJ, Bieschke J, Powers ET, Kelly JW. The oxidative stress metabolite 4hydroxynonenal promotes Alzheimer protofibril formation. Biochemistry. 2007;46:1503-10.

42. Brier MR, Gordon B, Friedrichsen K, McCarthy J, Stern A, Christensen J, Owen C, Aldea P, Su Y, Hassenstab J, et al. Tau and A beta imaging, CSF measures, and cognition in Alzheimer's disease. Sci Transl Med. 2016;8.

43. Kim JY, Lee HK, Jang JY, Yoo JK, Seong YH. llex latifolia prevents amyloid beta protein (25-35)-induced memory impairment by inhibiting apoptosis and tau phosphorylation in mice. J Med Food. 2015;18:1317-26.

44. Porquet D, Andres-Benito P, Grinan-Ferre C, Camins A, Ferrer I, Canudas AM, Del Valle J, Pallas M. Amyloid and tau pathology of familial Alzheimer's disease APP/PS1 mouse model in a senescence phenotype background (SAMP8). Age. 2015;37.

45. Zhou Z, Hou J, Mo Y, Ren M, Yang G, Qu Z, Hu Y. Geniposidic acid ameliorates spatial learning and memory deficits and alleviates neuroinflammation via inhibiting HMGB-1 and downregulating TLR4/2 signaling pathway in APP/PS1 mice. Eur J Pharmacol. 2020;869.

46. von Bernhardi R, Tichauer JE, Eugenin J. Aging-dependent changes of microglial cells and their relevance for neurodegenerative disorders. J Neurochem. 2010;112:1099-114.

47. Catalao CHR, Santos-Junior NN, da Costa LHA, Souza AO, Carnio EC, Sebollela A, Alberici LC, Rocha MJA: Simvastatin prevents long-term cognitive deficits in sepsis survivor rats by reducing neuroinflammation and neurodegeneration. Neurotoxicity research 2020

48. Liddelow SA, Barres BA. Reactive astrocytes: production, function, and therapeutic potential. Immunity. 2017:46:957-67.

49. Cavanagh C, Wong TP. Preventing synaptic deficits in Alzheimer's disease by inhibiting tumor necrosis factor alpha signaling. IBRO reports. 2018;4:18-21.

50. Wang Q, Jiang H, Wang L, Yi H, Li Z, Liu R. Vitegnoside mitigates neuronal injury, mitochondrial apoptosis, and inflammation in an Alzheimer's disease cell model via the p38 MAPK/JNK pathway. Journal Of Alzheimers Disease. 2019;72:199-214.

51. Kovac A, Zilka N, Kazmerova Z, Cente M, Zilkova M, Novak M. Misfolded truncated protein tau induces innate immune response via MAPK pathway. J Immunol. 2011;187:2732-9.

52. Wu ZH, Wong ET, Shi YL, Niu JX, Chen ZJ, Miyamoto S, Tergaonkar V. ATMand NEMO-dependent ELKS ubiquitination coordinates TAK1-mediated IKK activation in response to genotoxic stress. Mol Cell. 2010;40:75-86.

53. Joo SS, Won TJ, Lee DI. Potential role of ursodeoxycholic acid in suppression of nuclear factor kappa B in microglial cell line (BV-2). Arch Pharm Res. 2004;27:954-60.

54. Choi J, Kim J, Min DY, Jung E, Lim Y, Shin SY, Lee YH. Inhibition of TNFinduced interleukin-6 gene expression by barley (Hordeum vulgare) ethanol extract in BV-2 microglia. Genes \& Genomics. 2019;41:557-66.

55. Zhou C, Taslima F, Abdelhamid M, Kim S-W, Akatsu H, Michikawa M, Jung C-G. Beta-amyloid increases the expression levels of Tid 1 responsible for neuronal cell death and amyloid beta production. Mol Neurobiol. 2020;57:1099-114.

56. Hu YH, Zhang Y, Jiang LQ, Wang S, Lei CQ, Sun MS, Shu HB, Liu Y. WDFY1 mediates TLR3/4 signaling by recruiting TRIF. EMBO Rep. 2015;16:447-55.

57. Ejlerskov P, Hultberg JG, Wang J, Carlsson R, Ambjorn M, Kuss M, Liu Y, Porcu G, Kolkova K, Rundsten CF, et al. Lack of neuronal IFN-beta-IFNAR causes Lewy body- and Parkinson's disease-like dementia. Cell. 2015;163:324-39.

58. Hui B, Yao X, Zhang L, Zhou Q. Dexamethasone sodium phosphate attenuates lipopolysaccharide-induced neuroinflammation in microglia BV2 cells. Naunyn Schmiedeberg's Arch Pharmacol. 2020;393:1761-8.

59. Wang J, Jin Y, Li J. Protective role of fentanyl in lipopolysaccharide-induced neuroinflammation in BV-2 cells. Experimental And Therapeutic Medicine. 2018;16:3740-4.

60. Hong Q, Yang Y, Wang Z, Xu L, Yan Z. Longxuetongluo capsule alleviates lipopolysaccharide-induced neuroinflammation by regulating multiple signaling pathways in BV2 microglia cells. Journal of the Chinese Medical Association : JCMA. 2020;83:255-65.

61. Block ML, Zecca L, Hong J-S. Microglia-mediated neurotoxicity: uncovering the molecular mechanisms. Nat Rev Neurosci. 2007;8:57-69.

62. Li C, Chen T, Zhou H, Feng Y, Hoi MPM, Ma D, Zhao C, Zheng Y, Lee SMY. BHDPC is a novel neuroprotectant that provides anti-neuroinflammatory and neuroprotective effects by inactivating NF-kappa B and activating PKA CREB. Front Pharmacol. 2018;9.

\section{Publisher's Note}

Springer Nature remains neutral with regard to jurisdictional claims in published maps and institutional affiliations.

\section{Ready to submit your research? Choose BMC and benefit from}

- fast, convenient online submission

- thorough peer review by experienced researchers in your field

- rapid publication on acceptance

- support for research data, including large and complex data types

- gold Open Access which fosters wider collaboration and increased citations

- maximum visibility for your research: over $100 \mathrm{M}$ website views per year

At BMC, research is always in progress.

Learn more biomedcentral.com/submissions 